\title{
Erratum to: Accommodative changes in human eye observed by Kitasato anterior segment optical coherence tomography
}

\author{
Nobuyuki Satoh • Kimiya Shimizu • \\ Atsushi Goto • Akihito Igarashi - Kazutaka Kamiya • \\ Kohji Ohbayashi $\cdot$ Hiroyuki Furukawa
}

Published online: 2 April 2013

(C) Japanese Ophthalmological Society 2013

Erratum to: Jpn J Ophthalmol (2013) 57:113-119

DOI 10.1007/s10384-012-0208-6

The name Hiroyuki Furukawa was inadvertently omitted from the list of authors.

The online version of the original article can be found under doi:10.1007/s10384-012-0208-6.

N. Satoh $(\varangle) \cdot$ K. Shimizu · A. Igarashi · K. Kamiya Department of Ophthalmology, University of Kitasato School of Medicine, 1-15-1 Kitasato, Sagamihara,

Kanagawa 252-0374, Japan

e-mail: nosatou-ktz@umin.org

\section{A. Goto}

Canon Inc., Tokyo, Japan

K. Ohbayashi

Graduate School of Medical Sciences, University of Kitasato,

Sagamihara, Kanagawa, Japan

H. Furukawa

Center for Natural Science, Kitasato University,

Kanagawa, Japan 